\title{
Meaning in life and health care use: findings from a nationally representative study of older adults in Germany
}

\author{
André Hajek ${ }^{*}$ and Hans-Helmut König
}

\begin{abstract}
Background: There is a lack of studies examining the link between meaning in life and health care use. Meaning in life refers to a sense of comprehension and significance in life. Consequently, the purpose of this study was to investigate the association between meaning in life and health care use.

Methods: Cross-sectional data from the German Ageing Survey, a nationally representative sample of older adults, was used for this study (in the analytical sample: $n=3850$; year 2002). The frequency of GP and specialist visits in the past 12 months were used as outcome measures. Meaning in life was assessed using a single item measure. Based on Andersen's model, covariates were selected. Sex, age, family status, occupational status, income, self-rated health, physical functioning, depressive symptoms, and the number of physical illnesses were adjusted for in a multiple regression analysis.

Results: After adjusting for various potential confounders, there was a positive association between meaning in life and GP (IRR: 1.04, 95\%-Cl: 1.01-1.08) as well as specialist visits (IRR: 1.07, 95\%-Cl: 1.02-1.12) in a multiple regression analysis. With the exception of employment status (retired vs. employed), income and need factors, no covariates were consistently associated with both outcome measures.

Conclusions: This study highlighted the association between meaning in life and health care use. Our results indicate that there are other factors that are associated with health care use, beyond need-variables. This might help to identify individuals at risk for under- or overuse of health care services.
\end{abstract}

Keywords: Health care utilization, Health services needs and demand, Purpose in life, Meaning in life, Sense of life

\section{Background}

In order to be able to manage health care use, it is important to identify its determinants. Drawing on Andersen's behavioural model, there are numerous studies that have analysed the correlates of health care use (HCU). This model distinguishes between predisposing characteristics such as gender or age, enabling factors (e.g., income) and need factors (e.g., chronic illnesses or selfrated health). A systematic review concluded that need factors in particular shape HCU [1]. This is also important because need factors increases with age. Demographic ageing already places a considerable burden on health care systems $[2,3]$.

\footnotetext{
* Correspondence: a.hajek@uke.de

Department of Health Economics and Health Services Research, University Medical Center Hamburg-Eppendorf, Hamburg, Hamburg, Germany
}

However, some recent studies have demonstrated that other factors exist shown to be important for individuals' $\mathrm{HCU}$, even after adjusting for the factors mentioned in Andersen's behavioral model. For example, it has been demonstrated that psychological factors, personality characteristics or general locus of control are also important [4-9]. However, meaning in life has largely been unexplored in HCU research. According to Reker [10] meaning in life can be defined as "having a sense of direction, a sense of order and a reason for existence, a clear sense of personal identity, and a greater social consciousness" (p. 710). A landmark study by Kim et al. [11], for example, showed that purpose in life is associated with the use of several preventive health care services. However, as already argued by George and Park, meaning and purpose are two separate, but related,

(C) The Author(s). 2019 Open Access This article is distributed under the terms of the Creative Commons Attribution 4.0 International License (http://creativecommons.org/licenses/by/4.0/), which permits unrestricted use, distribution, and 
constructs [12]. For example, they differ in their correlates [12]. While meaning in life refers to a sense of comprehension and significance in life, purpose in life refers to a sense of goals, aims, as well as direction in life [12]. Furthermore, it is worth noting that the study by Kim et al. [11] focused on preventive health care services, whereas this study focuses on General Practitioner (GP) and specialist visits in general.

Hence, the purpose of this study was to investigate the association between meaning in life and HCU based on a large population-based sample of individuals $\geq 40$ years. Investigating individuals aged 40 and above is particularly relevant because need factors increase with age. With regard to possible mechanisms, when individuals do not perceive their life as meaningful, it is plausible that they would not invest in their health and therefore might report infrequent outpatient physician visits (e.g., underuse of preventive health care services). Knowledge about this association might help to address individuals at risk for infrequent doctor visits. This is important because randomized controlled trials have demonstrated that meaning in life can be modified [13, 14].

With respect to the health care system in Germany, it is worth noting that health insurance is compulsory. Approximately $90 \%$ of the population are enrolled in the statutory health insurance (SHI); the remaining 10\% are insured under the private health insurance (PHI). Selfemployed individuals, civil servants and individuals who exceed a certain income-threshold can choose between SHI and PHI. Both types provide comprehensive health care for their members. Outpatient specialists can be consulted without a GP referral. For further details with regard to the health care system in Germany, please see Busse et al. [15].

\section{Methods}

\section{Sample}

The current study used data from the German Ageing Survey (DEAS), which started in 1996 (first wave). For reasons of data availability, our study was restricted to the second wave, which took place in 2002, as our key independent variable was only assessed in the second wave.

The Federal Ministry for Family Affairs, Senior Citizens, Women and Youth funded the DEAS study. The DEAS study is a representative study of individuals residing in private households ( 40 years and over). Therefore, the main inclusion criterion was that individuals had to be at least 40 years old. More specifically, first time participants were included when they met the following criteria: [1] born between 1929 and 1974, [2] living in a private household (which means that individuals residing in institutionalized settings were excluded). For panel participants, inclusion criteria were: [1] one or more valid interviews in former waves, [2] willingness to participate in the panel (written consent given by baseline participants), [3] still alive and not living abroad. Various topics (e.g., perception of ageing, social support, health, occupational status, retirement) are covered in the DEAS study.

In the first wave, 4838 individuals were interviewed (50\% response rate) and 5194 individuals took part in the second wave ( $38 \%$ response rate). In the first wave, the gross sample included 9613 individuals. Thereof, 3268 individuals $(34.0 \%)$ refused participation. Other minor reasons for non-response were, for example, that individuals were temporary ill (108 individuals, $1.1 \%$ ) or permanently ill (383 individuals, 4.0\%). Neller showed that the response rate reported in the DEAS study is similar compared with other large survey studies that have taken place in Germany [16]. Klaus et al. provided additional details with regard to the DEAS study [17]. In our analytical sample (i.e., individuals included in regression analysis), $n=3850$ individuals were included (with number of specialist visits as outcome measure; $n=3844$ with number of GP visits as outcome measure).

Written informed consent was provided by all individuals. An ethical statement for the DEAS study was not needed, as the criteria for it were not met (e.g., examination of patients, risk for the respondents, or the use of invasive methods).

\section{Dependent variable}

The use of outpatient physician visits (first dependent variable: number of GP; second dependent variable: number of specialist visits) in the preceding 12 months was assessed in the DEAS study. Several medical specialties were reported in the DEAS study. The number of GP and specialist visits was quantified as: never; once; 2-3 times; 4-6 times; 7-12 times; more often. Following Bock et al. and Flennert et al. $[4,18]$, it was recoded as: "never" $=0$; "once" $=1$; "2-3 times" $=2.5$; " $4-6$ times" = 5; "7-12 times" $=9.5$; and "more often" $=13$.

\section{Independent variables}

A single item (based on WHOQOL-BREF [19]) with clear face validity was used to measure meaning in life: "To what extent do you feel your life to be meaningful?" $[1=$ not at all; $2=\mathrm{a}$ little; $3=\mathrm{a}$ moderate amount; $4=$ very much; $5=$ extremely]. A recent study has provided evidence for the reliability and validity of this single item measure [20].

Based on Andersen's behavioral model [21], covariates were selected. Namely, predisposing characteristics such as sex, age, marital status (married, and living together with spouse; married, and living separated from spouse; widowed; divorced; single), and occupational status (employed; retired; other: not employed) were controlled 
for. With regard to enabling factors, income (household net equivalent income) was adjusted for.

With regard to need variables, self-rated health (from $1=$ very good to $5=$ very bad), physical functioning (subscale physical functioning of the SF-36 [22]; ranging from $0=$ worst to $100=$ best $)$, depressive symptoms $(15$ item version of the Center for Epidemiological Studies Depression Scale [23], from 0 to 45, higher values correspond to more depressive symptoms), and the number of chronic illnesses such as diabetes or cancer (ranging from 0 to 11) were adjusted for.

In a sensitivity analysis, other factors that may affect the link between meaning in life and HCU were adjusted for, i.e. religious affiliation (protestant church (not including free churches), roman catholic church, another Christian community, another non-Christian community, no religious group), health locus of control (from $1=\mathrm{I}$ have practically no influence on my health to $4=\mathrm{I}$ have strong influence on my health) and network size (number of important people in regular contact, ranging from 0 to 9). In further sensitivity analysis, the continuous outcome measures were replaced by categorical outcome measures (please see the section dependent variables for categories).

\section{Statistical analysis}

First, sample characteristics were displayed. Subsequently, negative binomial regression analysis were conducted with GP and specialist visits as outcome measures, respectively [24]. Due to the nature of the data (count data; distribution of visits was positively skewed), we used this type of regression analysis [2426]. Further details with regard to negative binomial regressions are given by Hardin et al. [24]. Meaning in life was our key independent variable. Several potential confounders were adjusted for. The criterion for statistical significance was set at $p<.05$. Analyses were performed using Stata 15.1 (StataCorp, College Station, Texas, USA).

\section{Results}

\section{Sample characteristics}

Sample characteristics are depicted in Table 1. In total, $51.5 \%$ of the sample were male and the mean age was 61.0 years $( \pm 12.0$ years). Average meaning of life was 4.1 ( \pm 0.9 ; Variance: .79; Skewness: - 1.19; Kurtosis: 4.79), average GP visits were $4.2( \pm 3.7)$ and average specialist visits were $3.4( \pm 4.0)$. Further details are provided in Table 1.

\section{Regression analysis}

Findings of regression analysis are shown in Table 2 . The parameter estimates were converted to incidence rate ratios (IRRs) by exponentiation (for ease of
Table 1 Sample characteristics (wave $2 ; n=4655$ )

\begin{tabular}{|c|c|}
\hline Variables & $\begin{array}{l}\text { N (\%) / Mean } \\
\text { (SD) }\end{array}$ \\
\hline Sex: - Male: N (\%) & $2397(51.5 \%)$ \\
\hline - Female & $2258(48.5 \%)$ \\
\hline Age in years: Mean (SD) & $61.0(12.0)$ \\
\hline $\begin{array}{l}\text { Family status: - Married, living together } \\
\text { with spouse: } N(\%)\end{array}$ & $3364(72.3 \%)$ \\
\hline - Married, living separated from spouse & $91(2.0 \%)$ \\
\hline - Divorced & $377(8.1 \%)$ \\
\hline - Widowed & $579(12.4 \%)$ \\
\hline - Single & $242(5.2 \%)$ \\
\hline Employment status: - Employed: N (\%) & $1744(37.5 \%)$ \\
\hline - Retired & $2159(46.4 \%)$ \\
\hline - Other: not employed & $752(16.1 \%)$ \\
\hline Income (in Euro): Mean (SD) & $1455(813)$ \\
\hline $\begin{array}{l}\text { Self-rated health (from } 1=\text { very good to } 5=\text { very bad): } \\
\text { Mean (SD) }\end{array}$ & $2.5(0.9)$ \\
\hline Depressive symptoms: Mean (SD) & $7.5(6.6)$ \\
\hline Physical functioning: Mean (SD) & $83.5(23.6)$ \\
\hline Number of physical illnesses: Mean (SD) & $2.3(1.9)$ \\
\hline $\begin{array}{l}\text { Meaning in life (from } 1=\text { not at all to } 5=\text { extremely): } \\
\text { Mean (SD) }\end{array}$ & $4.1(0.9)$ \\
\hline GP visits in the past 12 months: Mean (SD) & $4.2(3.7)$ \\
\hline \multicolumn{2}{|l|}{ GP visits in the past 12 months: $\mathrm{N}(\%)$} \\
\hline "Never" & $600(12.9 \%)$ \\
\hline "Once" & 749 (16.1\%) \\
\hline "2-3 times" & $1249(26.8 \%)$ \\
\hline "4-6 times" & $1016(21.8 \%)$ \\
\hline "7-12 times" & $782(16.8 \%)$ \\
\hline "more often" & $259(5.6 \%)$ \\
\hline Specialist visits in the past 12 months: Mean (SD) & $3.4(4.0)$ \\
\hline
\end{tabular}

Notes: $\mathrm{N}=$ number; $\mathrm{SD}=$ standard deviation

interpretation). IRRs can be interpreted as the percent change in the outcome variable (GP or specialist visits) associated with a one-unit change in the independent variable (holding all other variables constant). The presence of multicollinearity was investigated based on the variance inflation criterion. The largest variance found was 3.13 , which shows that multicollinearity was not present. In the analytical sample, $n=3850$ individuals were included (with number of specialist visits as outcome measure; $n=3844$ with number of GP visits as outcome measure).

Adjusting for numerous potential confounders, multiple negative binomial regressions revealed that meaning in life was associated with GP (IRR: 1.04, 95\%-CI: 1.01-1.08) as well as specialist visits (IRR: 1.07, 95\%-CI: 1.02-1.12). With the exceptions of employment status (retired vs. employed), income and need factors 
Table 2 Determinants of GP as well as specialist visits. Results of negative binomial regressions

\begin{tabular}{|c|c|c|}
\hline Independent variables & GP visits & Specialist visits \\
\hline \multirow{2}{*}{$\begin{array}{l}\text { Meaning in life (from } 1=\text { not at } \\
\text { all to } 5=\text { extremely) }\end{array}$} & $1.04^{* *}$ & $1.07^{* *}$ \\
\hline & $(1.01-1.08)$ & $(1.02-1.12)$ \\
\hline \multirow[t]{2}{*}{ Female (Ref.: male) } & $1.05+$ & $1.78^{* * *}$ \\
\hline & $(1.00-1.11)$ & $(1.66-1.91)$ \\
\hline \multirow[t]{2}{*}{ Age } & $1.00+$ & $0.99^{*}$ \\
\hline & $(1.00-1.01)$ & $(0.99-1.00)$ \\
\hline \multirow{2}{*}{$\begin{array}{l}\text { Family status: - Married, living } \\
\text { separated from spouse } \\
\text { (Ref.: Married, living together } \\
\text { with spouse) }\end{array}$} & 0.94 & $1.34^{*}$ \\
\hline & $(0.77-1.16)$ & $(1.06-1.70)$ \\
\hline \multirow[t]{2}{*}{ - Divorced } & $0.91+$ & 1.03 \\
\hline & $(0.83-1.01)$ & $(0.91-1.16)$ \\
\hline \multirow[t]{2}{*}{ - Widowed } & 1.02 & $0.90+$ \\
\hline & $(0.94-1.10)$ & $(0.80-1.01)$ \\
\hline \multirow[t]{2}{*}{ - Single } & 0.94 & 0.94 \\
\hline & $(0.82-1.07)$ & $(0.79-1.11)$ \\
\hline \multirow{2}{*}{$\begin{array}{l}\text { Employment status: - Retired } \\
\text { (Reference: Employed) }\end{array}$} & $1.22^{* * *}$ & $1.22^{* *}$ \\
\hline & $(1.11-1.34)$ & $(1.08-1.38)$ \\
\hline \multirow[t]{2}{*}{ - Other: not employed } & 1.05 & $1.15^{* *}$ \\
\hline & $(0.96-1.15)$ & $(1.04-1.29)$ \\
\hline \multirow[t]{2}{*}{ Log income } & $0.88^{* * *}$ & $1.17^{* * *}$ \\
\hline & $(0.83-0.93)$ & $(1.08-1.27)$ \\
\hline \multirow{2}{*}{$\begin{array}{l}\text { Self-rated health (from } 1=\text { very } \\
\text { good to } 5=\text { very bad) }\end{array}$} & $1.27^{* * *}$ & $1.24^{* * *}$ \\
\hline & $(1.23-1.33)$ & $(1.18-1.31)$ \\
\hline \multirow{2}{*}{$\begin{array}{l}\text { Depressive symptoms (from } 0 \\
\text { (no depressive symptoms) } \\
\text { to } 45 \text { (severe depressive symptoms)) }\end{array}$} & $1.00^{*}$ & $1.01 * * *$ \\
\hline & $(1.00-1.01)$ & $(1.01-1.02)$ \\
\hline \multirow{2}{*}{$\begin{array}{l}\text { Physical functioning (from } 0 \\
\text { (worst) to } 100 \text { (best)) }\end{array}$} & $1.00^{* * *}$ & $1.00^{*}$ \\
\hline & $(1.00-1.00)$ & $(1.00-1.00)$ \\
\hline \multirow{2}{*}{$\begin{array}{l}\text { Number of physical illnesses } \\
\text { (from } 0 \text { to } 11 \text { ) }\end{array}$} & $1.09^{* * *}$ & $1.14^{* * *}$ \\
\hline & $(1.08-1.11)$ & $(1.11-1.16)$ \\
\hline \multirow[t]{2}{*}{ Constant } & $3.17^{* * *}$ & $0.20^{* * *}$ \\
\hline & $(1.87-5.38)$ & $(0.09-0.41)$ \\
\hline Observations & 3844 & 3850 \\
\hline Pseudo $R^{2}$ & .056 & .045 \\
\hline
\end{tabular}

(including self-rated health, depressive symptoms, physical functioning and number of physical illnesses), none of the covariates were consistently associated with both outcome measures.

We also tested for non-linearity by including (i) quadratic as well as (ii) cubic terms for meaning in life. However, they did not achieve statistical significance. Moreover, a sensitivity analysis was performed to test the robustness of our findings. Specifically, the main model was extended by adding religious affiliation, health locus of control and network size. However, the association between meaning in life and the outcome measures remained virtually the same (results not shown, but available upon request). Furthermore, we replaced the continuous outcome measures with categorical outcome measures (ordered probit regressions were used). However, in terms of significance, the association between meaning in life and the outcome measures remained almost the same (with GP visits as outcome measure: $\beta=.09, p<.001$; with specialist visits as outcome measure: $\beta=.09, p<.001$ ).

\section{Discussion \\ Main findings}

Using data from a nationally representative sample of older adults, the aim of this study was to investigate the association between meaning in life and HCU. After adjusting for various potential confounders (e.g., socioeconomic variables, physical functioning, depressive symptoms, number of physical illnesses and self-rated health), a positive association between meaning in life and GP as well as specialist visits was found in multiple regression analysis.

\section{Previous research and possible explanations}

There is a lack of studies to date that have examined the link between meaning in life and HCU in general. A few studies conducted by Kim and colleagues have investigated the link between use of preventive health care services and aging satisfaction, as well as life satisfaction, among older adults $[27,28]$. These studies showed that individuals scoring higher in aging satisfaction tend to use several preventive health care services (e.g., use for cholesterol tests, obtaining a mammogram/x-ray in women or obtaining a prostate exam in men) more often. Similar findings were made for the association between life satisfaction and the use of preventive health care services.

Furthermore, based on data from the Health and Retirement Study $(n=7168)$, another recent study conducted by Kim et al. [11] showed that purpose in life was positively associated with the use of different preventive health care services (such as mammogram/X-ray, pap smear or prostate examination) after adjusting for 
factors such as age, marital status, or an index of major chronic illnesses. This indicates that purpose in life is linked to health promoting behavior (in that individuals who score high in purpose in life may be more proactive in taking care of their health [11]) Therefore, it appears plausible to us that meaning in life, a closely related construct, was associated with HCU in general in our study (even after adjusting for several potential confounders).

Another way to explain our findings may be that individuals in the second half of life who score low in meaning in life might have a lack of drive, decreased health [29] or may feel that they do not belong to the society [30]. Therefore, these individuals may not see the value in visiting the doctor to maintain their health [31]. However, future research is required to elucidate the mechanisms by which meaning in life can affect HCU. The findings of our study provide first evidence on the relationship between meaning in life and $\mathrm{HCU}$ in general.

With regard to control variables, (e.g., need-factors like self-rated health) our findings are mostly in line with previous literature. For example, a systematic review conducted by Babitsch et al. [1] showed that increased needfactors in particular are associated with increased HCU.

It is interesting that, for example, worse self-rated health is associated with increased HCU in our study, whereas a low meaning in life is associated with decreased $\mathrm{HCU}$. We assume that the aforementioned factors (lack of energy, social isolation) may drive the link between meaning in life and HCU. At present, however, there is no evidence to support our assertion.

\section{Strengths and limitations}

This is the first study investigating the association between meaning in life and HCU based on a large nationally representative sample of older adults in Germany. Based on Andersen's theoretical model, various covariates were included. There is some sample selectivity in the DEAS study. For example, participation rates are lower among, for example, among women, middle-aged (40 to 54 years) and individuals from 70 to 85 years. Further details are given by Klaus et al. [17]. However, this sample selection bias was not found to be important in the DEAS study [17]. A single item was used to measure meaning in life. The underlying reason for physician visits (e.g., preventive or curative) remains unclear. As far as data are available, future studies should investigate whether the link between meaning in life and HCU varies by the reason for consultation. Moreover, data from the second wave of the DEAS study (taking place in 2002) were used. Thus, we cannot dismiss the possibility that the link between meaning in life and HCU differs between past and present cohorts. On the one hand, there might be cohort effects with respect to the meaning of life ("Zeitgeist"). The accessibility of physicians might also have changed (e.g. in terms of waiting times).

Future studies are required to validate our findings based on instruments that are more sophisticated (e.g., meaning in life questionnaire [32]). Furthermore, longitudinal studies are required to establish the long-term role of meaning in life on HCU.

\section{Conclusions}

This study highlighted the association between meaning in life and HCU. Thus, our results indicate that beyond need-variables other factors exist that are associated with HCU. This might help to identify individuals at risk for under- or overuse of health care services.

\section{Abbreviations}

DEAS: German Ageing Survey; GP: General Practitioner; HCU: Health care use; IRR: Incidence rate ratio; PHI: Private health insurance; SF-36: Short Form 36; SHI: Statutory health insurance; WHOQOL-BREF: World Health Organization Quality of Life Brief Version

\section{Acknowledgements}

Not applicable.

\section{Authors' contributions}

AH, HHK: Design and concept of analyses, preparation of data, statistical analysis and interpretation of data, preparing of the manuscript. Both authors critically reviewed the manuscript, provided significant editing of the article and approved the final manuscript.

\section{Funding}

Not applicable.

\section{Availability of data and materials}

The data used in this study are third-party data. The anonymized data sets of the DEAS $(1996,2002,2008,2011,2014$, and 2017) are available for secondary analysis. The data has been made available to scientists at universities and research institutes exclusively for scientific purposes. The use of data is subject to written data protection agreements. Microdata of the German Ageing Survey (DEAS) is available free of charge to scientific researchers for nonprofitable purposes. The FDZ-DZA provides access and support to scholars interested in using DEAS for their research. However, for reasons of data protection, signing a data distribution contract is required before data can be obtained. Please see for further information (data distribution contract): https://www.dza.de/en/fdz/german-ageing-survey/access-to-deas-data.html

\section{Ethics approval and consent to participate}

Written informed consent was provided by all individuals. An ethical statement for the DEAS study was not needed, as the criteria for it were not met (e.g., examination of patients, risk for the respondents, or the use of invasive methods).

\section{Consent for publication}

Not applicable.

\section{Competing interests}

The authors declare that they have no competing interests.

Received: 11 June 2019 Accepted: 16 December 2019

Published online: 23 December 2019

\section{References}

1. Babitsch B, Gohl D, von Lengerke T. Re-revisiting Andersen's behavioral model of health services use: a systematic review of studies from 1998 2011. GMS PsychoSoc Med. 2012;9:Doc 11. 
2. Lloyd-Sherlock P. Population ageing in developed and developing regions: implications for health policy. Soc Sci Med. 2000;51(6):887-95.

3. Stahl T, Wismar M, Ollila E, Lahtinen E, Leppo K. Health in all policies. Prospects and potentials. Ministry of Social Affairs and Health: Helsinki; 2006.

4. Bock JO, Hajek A, König HH. The longitudinal association between psychological factors and health care use. Health Serv Res. 2018:53(2):1065-91.

5. Fenton JJ, Magnan EM, Jerant A, Kravitz RL, Franks P. Patient characteristics associated with making requests during primary care visits. J Am Board Fam Med. 2019;32(2):201-8

6. Friedman B, Veazie PJ, Chapman BP, Manning WG, Duberstein PR. Is personality associated with health care use by older adults? Milbank Q. 2013;91(3):491-527.

7. Hajek A, Bock J-O, König H-H. The role of personality in health care use: results of a population-based longitudinal study in Germany. PLoS One. 2017:12(7):e0181716

8. Hajek A, König HH. Locus of control and frequency of physician visits: results of a population-based longitudinal study in Germany. Br J Health Psychol. 2017;22(3):414-28.

9. Progovac AM, Pettinger M, Donohue JM, Chang C-CHJ, Matthews KA Habermann EB, et al. Optimism may moderate screening mammogram frequency in Medicare: a longitudinal study. Medicine. 2019:98(24):e15869.

10. Reker GT. Personal meaning, optimism, and choice: existential predictors of depression in community and institutional elderly. The Gerontologist. 1997; 37(6):709-16.

11. Kim ES, Strecher VJ, Ryff CD. Purpose in life and use of preventive health care services. Proc Natl Acad Sci. 2014;111(46):16331-6.

12. George LS, Park CL. Are meaning and purpose distinct? An examination of correlates and predictors. J Posit Psychol. 2013;8(5):365-75.

13. Breitbart W, Poppito S, Rosenfeld B, Vickers AJ, Li Y, Abbey J, et al. Pilot randomized controlled trial of individual meaning-centered psychotherapy for patients with advanced cancer. J Clin Oncol. 2012;30(12):1304-9.

14. van der Spek N, Vos J, van Uden-Kraan CF, Breitbart W, Cuijpers P, Knipscheer-Kuipers $K$, et al. Effectiveness and cost-effectiveness of meaningcentered group psychotherapy in cancer survivors: protocol of a randomized controlled trial. BMC Psychiatr. 2014;14(1):22.

15. Busse R, Riesberg A, Organization WH. Health care systems in transition: Germany. WHO Regional Office for Europe: Copenhagen; 2004.

16. Neller K. Kooperation und Verweigerung. Eine non-response-Studie [cooperation and refusal: a non-response study]. ZUMA Nachrichten. 2005; 29(57):9-36.

17. Klaus D, Engstler H, Mahne K, Wolff JK, Simonson J, Wurm S, et al. Cohort profile: the German Ageing Survey (DEAS). Int J Epidemiol. 2017:46(4):1105$1105 \mathrm{~g}$.

18. Flennert $\mathrm{M}$, König $\mathrm{H}-\mathrm{H}$, Hajek $\mathrm{A}$. The association between voluntary work and health care use among older adults in Germany. BMC Health Serv Res. 2019;19(1):39.

19. Group W. Development of the World Health Organization WHOQOL-BREF quality of life assessment. Psychol Med. 1998;28(3):551-8.

20. Atroszko P, Krzyżaniak P, Sendal L, Atroszko B. Validity and reliability of single-item self-report measures of meaning in life and satisfaction with life. Compar Eur Res. 2015;2:212-5.

21. Andersen RM. Revisiting the behavioral model and access to medical care: does it matter? J Health Soc Behav. 1995;36:1-10.

22. Ware JE Jr, Sherbourne CD. The MOS 36-item short-form health survey (SF36): I. conceptual framework and item selection. Med Care. 1992:30:473-83.

23. Lehr D, Hillert A, Schmitz E, Sosnowsky N. Screening depressiver störungen mittels allgemeiner depressions-skala (ADS-K) und state-trait depressions scales (STDS-T) eine vergleichende evaluation von Cut-off-werten. Diagnostica. 2008;54(2):61-70.

24. Hardin JW, Hardin JW, Hilbe JM, Hilbe J. Generalized linear models and extensions. Texas: Stata; 2007.

25. Afifi AA, Kotlerman JB, Ettner SL, Cowan M. Methods for improving regression analysis for skewed continuous or counted responses. Annu Rev Public Health. 2007:28:95-111.

26. Atkins DC, Gallop RJ. Rethinking how family researchers model infrequent outcomes: a tutorial on count regression and zero-inflated models. J Fam Psychol. 2007;21(4):726

27. Kim ES, Kubzansky LD, Smith J. Life satisfaction and use of preventive health care services. Health Psychol. 2015;34(7):779.

28. Kim ES, Moored KD, Giasson HL, Smith J. Satisfaction with aging and use of preventive health services. Prev Med. 2014;69:176-80.
29. Musich S, Wang SS, Kraemer S, Hawkins K, Wicker E. Purpose in life and positive health outcomes among older adults. Popul Health Manag. 2018; 21(2):139-47.

30. Neville S, Adams J, Montayre J, Larmer P, Garrett N, Stephens C, et al. Loneliness in men 60 years and over: the association with purpose in life. Am J Mens Health. 2018;12(4):730-9.

31. Vozikaki M, Linardakis $M$, Philalithis $A$. Preventive health services utilization in relation to social isolation in older adults. J Public Health. 2017;25(5):545-56.

32. Steger MF, Frazier $P$, Oishi $S$, Kaler M. The meaning in life questionnaire: assessing the presence of and search for meaning in life. J Couns Psychol. 2006;53(1):80.

\section{Publisher's Note}

Springer Nature remains neutral with regard to jurisdictional claims in published maps and institutional affiliations.
Ready to submit your research? Choose BMC and benefit from:

- fast, convenient online submission

- thorough peer review by experienced researchers in your field

- rapid publication on acceptance

- support for research data, including large and complex data types

- gold Open Access which fosters wider collaboration and increased citations

- maximum visibility for your research: over $100 \mathrm{M}$ website views per year

At $\mathrm{BMC}$, research is always in progress.

Learn more biomedcentral.com/submissions 